\title{
A severe case of conjunctival papilloma in a five year old female
}

\author{
Oseluese Anastasia Dawodu* and Valentina Okeigbemen \\ Department of Ophthalmology, University of Benin Teaching Hospital, Benin City, Nigeria
}

\begin{abstract}
Conjunctival papilloma is a benign growth arising from the stratified squamous epithelium of the conjunctiva. It is sometimes described as benign and self limiting and known to occur in both children and adults. The case of a five year old girl who was seen at the University of Benin Teaching Hospital with severe, long standing, bilateral squamous cell papilloma is presented. She had a twelve month history of multiple growths in the conjunctiva of both eyes. Over time, the growths gradually covered most of the palpebral fissure in both eyes. They resulted in visual impairment from obliteration of the gap between the lids when the eyes are open due to the dense, tightly packed fleshy new growth in both eyes, worse in the left eye. The patient's management involved: Excisional biopsy in both eyes under general anaesthesia, intraoperative use of Mitomycin $\mathrm{C}$ and post operative use of Targamet tablets $200 \mathrm{mg}$ BD to prevent recurrence. The definitive histological diagnosis was benign conjunctival papilloma. Various treatment modalities for conjunctival papilloma have been described in the literature. These include conservative management, surgical excision, topical interferon alpha-2b, Carbon dioxide laser, and cryoablation. Mitomycin $\mathrm{C}$ has been used as an adjunct therapy after surgical debulking. Excision biopsy was chosen as the treatment modality in this patient due to the level of severity at presentation and the fact that the conjunctiva masses interfered with vision. None of the previously reported complications of use of Mitomycin $\mathrm{C}$ occurred in this patient.
\end{abstract}

\section{Introduction}

Conjunctival papilloma is a benign growth arising from the stratified squamous epithelium of the conjunctiva [1]. They are known to occur in both children and adults but they are most common in the age group 20-39 years. A male preponderance of $60 \%$ has been reported $[2,3]$. The aetiology is not established but human papilloma virus (HPV) is thought to be an important factor. HPV is a family of double stranded DNA virus of which over 80 types have been identified. Types $6,11,16$ and 18 have been identified in conjunctival papillomas [3].

HPV has also been demonstrated in normal conjunctiva [4]. The transmission route of HPV to the conjunctiva has not been clarified. It may be from fetal passage through infected birth canal [2]. Autoinoculation cannot be ruled out as HPV in ocular swabs have been found in women with HPV induced lesions in the genital tract [3].

Squamous cell papilloma is benign and self limiting, may be unilateral or bilateral and solitary or multiple [5]. Most lesions are asymptomatic and without associated conjunctivitis and folliculitis. Anatomically it is commonly located in the inferior fornix, but it may also arise from the limbus, caruncle and palpebral regions. Grossly, they appear as a greyish red, fleshy, soft, pedunculated mass with an irregular surface (cauliflower like) [3].

\section{Case report}

Patient is a five year old female who presented at the Eye Clinic of the University of Benin Teaching Hospital with a 12 month history of multiple growths in the conjunctiva of both eyes. The area covered by the growths has been increasing over time and has gradually covered most of the palpebral fissure in both eyes. There was difficulty seeing through the little gap between the lids when the eyes are open due to the dense tightly packed fleshy new growth in both eyes, worse in the left eye (Figures 1-3).
Local anaesthetic drops were applied to both eyes and a speculum inserted into the conjunctival sac to allow a more detailed ocular examination. The bulbar conjunctiva was found to have a few fleshy growths, while most of the growths were arising from the tarsal conjunctiva. There was colour variation of the different segments of the fleshy growths. The cornea, anterior chamber and pupil were normal and there was a normal red reflex through the pupil (Figure 4).

An excisional biopsy was done under general anaesthesia. The histological diagnosis was 'benign conjunctival papilloma'. Some of the growths were found to be pedunculated, while some had a broad base.

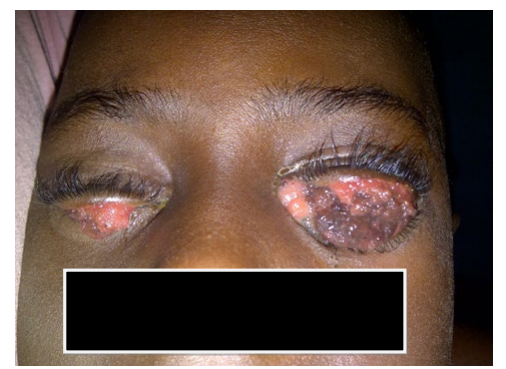

Figure 1. Both eyes with the eyelids at rest (The patient is unable to see due to the tumour masses).

Correspondence to: Prof. Oseluese Anastasia Dawodu [MBBS, FMC(Ophthal), FWACS, FICS], Professor of Ophthalmology, University of Benin Head, Paediatric Ophthalmology and Strabismus Unit, Department of Ophthalmology, University of Benin Teaching Hospital, Benin City, Nigeria; Tel: (Cell) +234703 2073082; E-mail: oseluesed@yahoo.com

Key words: conjunctival, papilloma, cimetidine, child

Received: April 01, 2016; Accepted: April 30, 2016; Published: May 05, 2016 


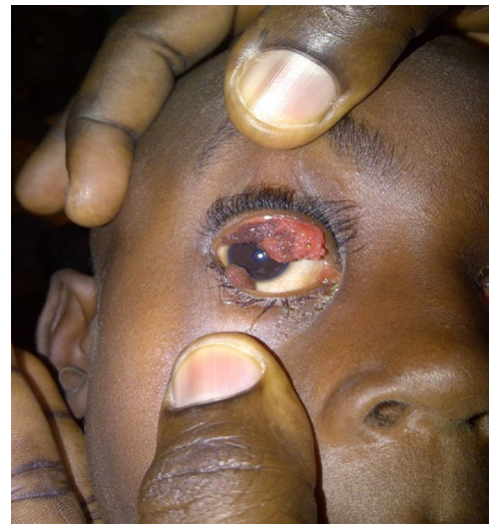

Figure 2. The conjunctival lesions in the right eye with the lids parted.

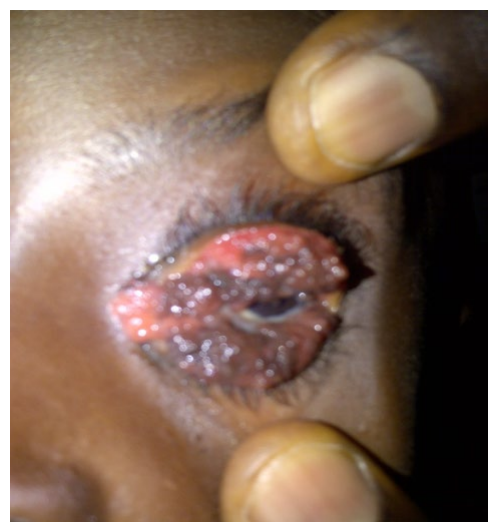

Figure 3.Conjunctival lesions in the left eye with the lids parted.

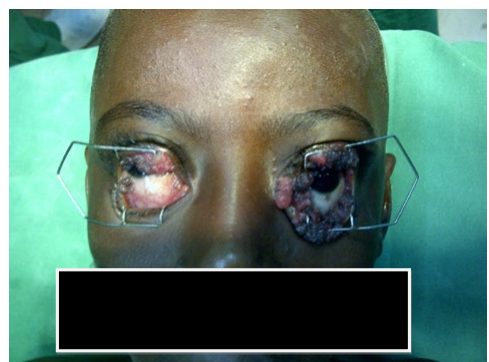

Figure 4. Appearance of the globes on parting the lids maximally (Immediate pre operative period).

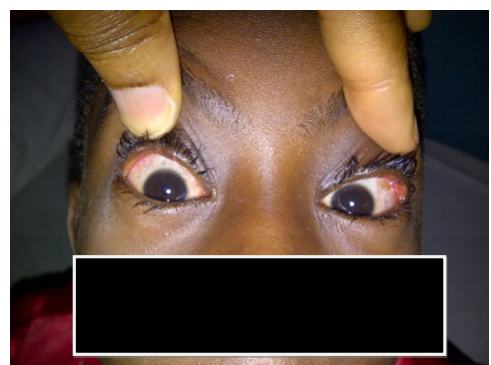

Figure 5. Both eyes looking normal one week after surgery.

The attachment of the growth to the conjunctiva was either ligated or clamped with artery forceps, and then excised. Bleeding was minimal and controlled with cautery when indicated. Mitomycin C $(0.3 \mathrm{mg} / \mathrm{ml})$ was applied to the base of the growths for 3 minutes before irrigating copiously, with normal saline. The procedure was repeated for the right eye. The excised tissues again were sent for histology. Subconjunctival Gentamicin $0.5 \mathrm{mls}$ was given post operatively in both eyes and topical Chloramphenicol eye drops and ointment applied. The patient was also placed on Cimetidine (Tagamet) tablets $100 \mathrm{mg}$ twice daily. The patient was discharged from the hospital the following day, with much improved ability to open the eyes, better cosmetic appearance and mild lid swelling and conjunctival injection. Figure 5 shows the same patient at first post follow-up visit, one week after surgery. The definitive histological diagnosis was benign conjunctival papilloma. There has been no recurrence 10 months after surgery. The patient is still being followed up for possible recurrence.

\section{Discussion}

Various treatment modalities for conjunctival papilloma have been described in the literature [6]. It could be conservative or surgical. Conservative treatment involves observation and patient reassurance, as lesions may regress spontaneously [7]. Topical interferon alpha $-2 b$ has been shown to be an effective adjunct therapy for small to medium sized lesions, but not for large lesions without surgical debulking $[8,9]$. Cryotherapy is recommended in the treatment of papillomas as it causes minimal scaring and rate of recurrence is low. The double-freeze-thaw method is preferred and appears to be the most effective technique [10]. Topical Antimetabolites like Mitomycin C and 5 Fluorouracil are also known treatment modalities though Mitomycin $\mathrm{C}$ is more commonly used as an adjunct therapy to surgical excision. Carbon dioxide $\left(\mathrm{CO}_{2}\right)$ laser has been found to be safe and effective. Dinitrochlorobenzene (DNCB) is reserved for cases where surgical excision, cryoablation, and other treatment modalities have failed [7,11].

Surgical care is indicated in cases where the lesion is causing significant symptoms, (cosmetically disfiguring, has not regressed, appearance of new lesions) [7]. An excisional biopsy is preferable to an incisional biopsy whenever possible. In the paediatric age group, the risk of general anaesthesia must be weighed against conservative management in mild cases. The late presentation of this patient to hospital resulted in visual impairment. The conjunctival masses effectively prevented light from getting into the eye when the lids are in normal position. Since the visual system is not fully developed at age 5 years, there was a risk of developing amblyopia if left untreated. Other treatment modalities such as topical use of anti metabolites like Mitomycin or cryotherapy may have been entertained if she presented early. Excisional biopsy is indicated in adults to rule out pre malignant changes [7].

Excision biopsy was chosen as the treatment modality in this patient due to the level of severity at presentation and the fact that the conjunctiva masses interfered with vision. Intraoperative Mitomycin C $(0.3 \mathrm{mg} / \mathrm{ml})$ was applied via cellulose sponge to the involved areas after excision to prevent recurrence. None of the previously reported ${ }^{7}$ complications of use of Mitomycin such as symblepharon, corneal oedema, corneal perforation, iritis, cataract and glaucoma occurred in this patient.

Though some of the lesions appeared to cover the cornea, in most cases they were attached to a small base near the limbus and overlying the cornea. Hence it could be lifted off the cornea and removed by severing the stalk near the limbus. None of the lesions seen in this case had its origin from the cornea. Seeding may occur following excision, resulting in multiple new lesions [7]. Therefore, to further guard against recurrence, oral Cimetidine (Tagamet) was given in a dose of $100 \mathrm{mg}$ BD. Cimetidine is a drug commonly used to treat peptic ulcer disease 
and has been shown to be effective in the treatment of recalcitrant conjunctival papilloma [7]. Apart from the antagonistic effect on $\mathrm{H} 2$ receptors, Cimetidine has been found to enhance the immune system by inhibiting suppressor $\mathrm{T}$-cell function and augmenting delayed -type hypersensitivity responses $[12,13]$.

\section{Conclusion}

This case highlights the need to intensify health education and awareness campaigns especially in rural areas. Making health care accessible and affordable to rural dwellers will go a long way in reducing the rate of very late presentation of patients to appropriate health facilities. Making the services of ophthalmologists available on part time basis to primary and secondary health facilities which are closer to the patients than the tertiary centres could prevent patients from presenting at such late stages of the disease process.

\section{References}

1. Farah S, Baum TD, Conlon MR, Alfonso EC, Starck T, et al. (2000) Tumours of the cornea and conjunctiva. In: Principles and Practice of Ophthalmology. Albert DM, Jakobiec FA, (eds) 2nd ed. Pennsylvania: W.B Saunders: 1002-19

2. Shields CL, Shields JA (2007) Conjunctivaltumors in children. Curr Opin Ophthalmol 18:351-360. [Crossref]

3. Sjö N, Heegaard S, Prause JU (2000) Conjunctival papilloma Ahistopathologically based retrospective study. Acta Ophthalmol. Scand 78: 663-666. [Crossref]
4. Karcioglu ZA, Issa TM (1997) Human papilloma virus in neoplastic and non-neoplastic conditions of the external eye. Br J Ophthalmol 81: 595-598. [Crossref]

5. Kaliki S, Arepalli S, Shields CL, Klein K, Sun H, et al. (2013) Conjunctival Papilloma Features and Outcomes Based on Age at Initial Examination. JAMA Ophthalmol 131: 585-593. [Crossref]

6. Kanski JJ, Bowling B, eds. Conjunctival papilloma. In: Clinical Ophthalmology: a systematic approach. $7^{\text {th }}$ ed. Elsevier Saunders; 2011: 476

7. Duong HQ, Copeland R: Conjunctiva Papilloma. Available from: http:// emedicine. medscape.com/article/1192618[accessed on $24^{\text {th }}$ January 2014].

8. Schechter BA, Rand WJ, Velazquez GE, Williams WD, Starasoler L (2002) Treatment of conjunctival papillomata with topical interferon Alfa-2b. Am J Ophthalmology 134: 268-270. [Crossref]

9. De Keizer RJ W, De Wolff-Rouendaal (2003) Topical a-interferon in Recurrent Conjunctival Papilloma. Acta Ophthalmologica Scandinavica 193-196.De Keizer RJ W, De Wolff-Rouendaal (2003) Topical a-interferon in Recurrent Conjunctival Papilloma. Acta Ophthalmologica Scandinavica 193-196.

10. Conjunctival Papilloma (2003) Acta Ophthalmologica Scandinavica 193-196.

11. Hon-Vu Q Duong, Hampton Roy, Copeland R A, Plager S D. et al. Conjunctival Papilloma Treatment \& Management (MEDSCAPE Updated: Jun 6, 2013)

12. Petrelli R, Cotlier E, Robins S, Stoessel K (1981) Dinitrochlorobenzene immunotherapy of recurrent squamous papilloma of the conjunctiva. Ophthalmology 88:1221-1225. [Crossref]

13. Shields CL, Lally MR, Singh AD, Shields JA, Nowinski T (1999) Oral cimetidine (Tagamet) for recalcitrant, diffuse conjunctivalpapillomatosis. Am J Ophthalmology 128:362-364. [Crossref]

Copyright: $@ 2016$ Dawodu OA. This is an open-access article distributed under the terms of the Creative Commons Attribution License, which permits unrestricted use, distribution, and reproduction in any medium, provided the original author and source are credited. 